\title{
Effects of hippocampal lesions on food and water consumption in rats'
}

D. P. KIMBLe AND G. D. COOVER UNIVERSITY OF OREGON

Rats with bilateral hippocampal lesions drank $16-21 \%$ more water postoperatively than Ss receiving posterior neocortical lesions or unoperated controls. Data were based on ad lib intake measures over 2 months following surgery. Both lesioned groups consumed slightly more food than unoperated Ss. No differences in body weights developed.

The manner in which the hippocampal formation participates in behavior remains in doubt. However, Green (1964) and Grastyan et al (1965) have suggested that the clear anatomical connections between the hippocampus and the hypothalamus may provide functional clues, and Pribram (1960) and de Groot (1965) have theorized that the limbic system may act to bias or modulate hypothalamic homeostats regulating the organisms milieu interieur. Since there is little direct evidence in rats regarding the role of the hippocampus in the regulation of food and water intake, the present experiment was undertaken to explore this problem by examining ad lib food and water consumption in rats with hippocampal lesions.

\section{Method}

Ss were 39 male, experimentally naive SpragueDawley rats obtained from Carworth Farms, N. Y., 70 days old at the beginning of the experiment. There were 15 unoperated controls. Twelve Ss received bilateral hippocampal lesions, and 12 received bilateral lesions of the neocortex overlying the hippocampus. All operations were performed over a 13 day span by aspiration in one stage, under Nembutal $(50 \mathrm{mg} / \mathrm{kg}$ ) anesthesia, as detailed previously (Kimble, 1963).

Food (Simonsen's white diet) and water were continually available. Daily ad lib food and water consumption measures were taken for 10 days prior to surgery. A container under each cage caught crumbs; these as well as leftover food were weighed so that any differential "sloppiness"' would be detected. Leakage from the water bottles was measured as $<2 \%$ of the average preoperative daily intake. Three experimental groups were made up on the basis of these preoperative consumption measures to insure equal preoperative

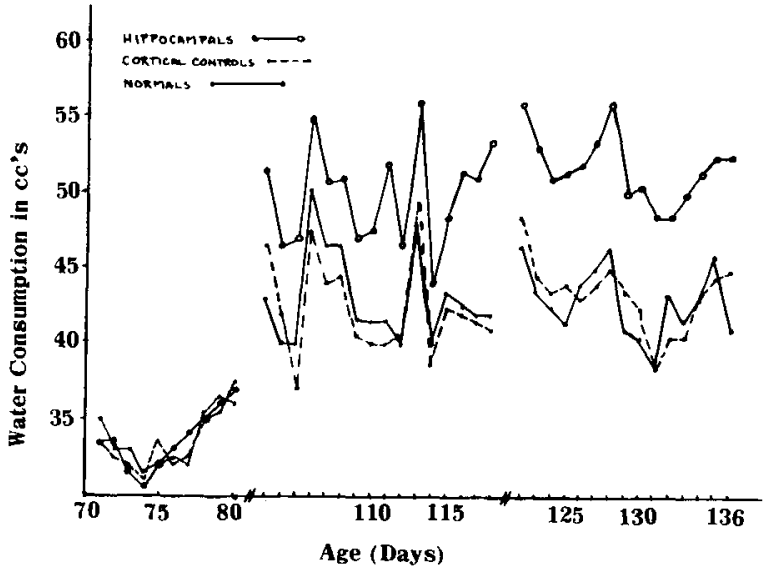

group means. The preoperative consumption was compared with that for two postoperative periods; Period 1 lasting from Day 20-38 after the first surgical day, and Period 2 lasting from Day 42-59.

\section{Results}

The hippocampal rats consumed $21 \%$ more water than either of the other experimental groups during Period 2; 16\% more during Period 1 (see Figure). A mean daily intake measure was obtained by collapsing data over each of the three periods for each S. A test of the validity of the assumptions underlying the analysis of covariance was significant. This was due to a difference in regression line slopes (for Period 2, the slopes are $1.27,-.002$, and 1.93 for normals, cortical operates, and hippocampals, respectively). There was, therefore, an interaction between the locus of the lesion and preoperative drinking level. Only the slope for the cortical operates was significantly different from the other two. Since the planned analysis of covariance was not allowable, a rank order test was performed. For Period 1, $\chi^{2}=4.3(.1<\mathrm{p}<.2)$ and for Period 2, $\chi^{2}=8.0(p<.025)$. The difference between the hippocampal Ss and either of the other groups for Period 2 was significant $(p<.025)$ with a Wilcox-Mann-Whitney test.

Table 1. Mean and standard deviations, daily food and water consumption: Normal, cortical operates and hippocampal rats.

\begin{tabular}{|c|c|c|c|c|c|c|c|}
\hline \multirow[t]{2}{*}{ Group } & \multirow[t]{2}{*}{$\mathrm{N}$} & \multicolumn{4}{|c|}{ Postoperative } & \multirow[b]{2}{*}{$\begin{array}{l}\text { Period } 2 \\
\text { Food }\end{array}$} & \multirow[b]{2}{*}{ Water } \\
\hline & & Food & Water & $\begin{array}{l}\text { Period } 1 \\
\text { Food }\end{array}$ & Water & & \\
\hline $\begin{array}{l}\text { Unoperated } \\
\text { Cortical operates } \\
\text { Hippocampals }\end{array}$ & \begin{tabular}{l|}
$14^{2}$ \\
12 \\
12 \\
\end{tabular} & $\begin{array}{l}21.2( \pm 2.0) \\
21.0( \pm 1.6) \\
21.2( \pm 1.3)\end{array}$ & $\begin{array}{ll}33.7 & ( \pm 6.9) \\
33.5 & ( \pm 5.5) \\
33.6 & ( \pm 4.3)\end{array}$ & $\begin{array}{l}21.9( \pm 1.6) \\
22.7( \pm 1.9) \\
23.2( \pm 1.7)\end{array}$ & $\begin{array}{l}42.8( \pm 10.0) \\
42.2( \pm 6.6) \\
49.6( \pm 10.6)\end{array}$ & $\begin{array}{l}20.7( \pm 1.5) \\
21.3( \pm 1.4) \\
21.8( \pm 1.5)\end{array}$ & $\begin{array}{l}43.1( \pm 10.7) \\
43.1 \pm 6.4) \\
52.1( \pm 10.3)\end{array}$ \\
\hline
\end{tabular}


Comparison of individual means also revealed that while the hippocampal Ss ate significantly more food $(<.05)$ than the unoperated Ss, for each of the 2 periods, the cortical operates fell in the middle, and did not differ significantly from either of the other groups. Throughout the consumption measurement periods, the group means of body weight were practically identical, varying $<3 \%$ among groups. Operated Ss typically regained their preoperative body weight by the 6 th postoperative day.

\section{Discussion}

The increased water consumption in the hippocampal rats is the major finding of this experiment. This finding is complicated somewhat by the interaction between lesion locus and preoperative drinking levels. A possible interpretation is that the increased drinking due to lesion is a percentage of preoperative intake, which would account for the increased slope of the hippocampal rats. For the cortical operates, who show a decrease if they are initially big drinkers but cannot withstand much drop if they are small drinkers, this results in a more marked decrease in regression line slope, but less marked decrease in group mean.

The intermediate position of the cortical operates on food consumption makes it likely that the removal of neocortical tissue as well as the paleocortical tissue of the hippocampus may be a factor in the slight increase in postoperative eating observed in our rats.

The increased water consumption in the hippocampal rats appears related to the data of Harvey \& Hunt (1965). They found a 37-59\% increase in ad lib water intake following septal lesions in Sprague-Dawley rats. The anatomical connection between the septal nuclei and the hippocampus (the fornix) is well known. Whether our hippocampal Ss will also behave such as to maximize the number of rewards in water reinforced operant situations as did the septal rats of Harvey \& Hunt (1965) is now under investigation, although Clark \& Isaacson (1965) have already reported that their hippocampal Ss did not so behave on either a DRL or CRF schedule.
It is not possible at this stage to explain the increased water consumption. Kim (1960) has reported that small, electrolytic lesions did not affect basal metabolic rate in rats. It is possible that our effects are related to the effects of septal lesions on adrenal function(Lissak \& Endroczi, 1961). Whatever the explanation, the present data indicate that it may be necessary to take account of possible increases in water consumption when evaluating the behavior of rats with hippocampal lesions.

\section{References}

Clark, C. V. H., \& Isaacson, R. L. Effect of bilateral hippocampal ablation on DRL performance. J. comp. physiol. Psychol., 1965, $59,137-140$.

de Groot, J. The influence of limbic structures on pituitary functions related to reproduction. In F. A. Beach (Ed.), Sex and behavior, New York: Wiley, 1965. Pp. 496-511.

Grastyan, E., Karmos, G., Vereczkey, L., Martin, J., \& Kellenyi, L. Hypothalamic motivational processes as reflected by their hippocampal electrical correlates. Science, 1965, 149, 91-93. Green, J. D. The hippocampus. Physiol. Rev., 1964, 44, 561-608.

Harvey, J. A., \& Hunt, H. F. Effect of septal lesions on thirst in the rat as indicated by water consumption and operant responding for water reward. J. comp. physiol. Psychol., 1965, 59, 49-56.

Kim, C. Nest-building, general activity, and salt preference of rats following hippocampal ablation. J. comp. physiol. Psychol., $1960,53,11-16$.

Kimble, D. P. The effects of bilateral hippocampal lesions in rats. J. comp. physiol. Psychol., 1963, 56, 273-283.

Lissak, K., \& Endroczi, E. Neurohumoral factors in the control of animal behaviour. In J. F. Delafresnaye (Ed.), Brain mechanisms and learning. Springfield, Illinois: Charles C. Thomas, 1961. Pp. 293-308.

Pribram, K. H. A review of theory in physiological psychology. Annu. Rev. Psych., 1960, 11, 1-40.

\section{Notes}

1. This investigation was supported in part by a USPHS Grant MH 08545-02, D. P. Kimble, principal investigator, and a USPHS predoctoral fellowship to G. D. Coover.

2. The data from one unoperated $\mathbf{S}$ was discarded because hïs water intake tripled within 3 weeks of the preoperative period. Statistical tests for outliers revealed that he was an outlier ( $p<$ .005 ). Inclusion of his data does not affect the food results at all, and the effect on the water results is to lower all probability levels to $<.05$. 